\title{
TRABALHO DOCENTE NAS UNIVERSIDADES FEDERAIS: tensões e contradições
}

\author{
Denise Lemos ${ }^{*}$
}

\begin{abstract}
Este artigo analisa o trabalho docente nas Universidades Federais, em especial na Universidade Federal da Bahia, entre 2005 e 2008, a partir do fenômeno da precarização social do trabalho e da consequente alienação do trabalhador, baseando-se nos resultados de pesquisa de doutorado realizada na UFBA. Descreve as dimensões fundamentais desse processo: a multiplicidade de tarefas, a captação de recursos internos e externos para a pesquisa, as contradições entre a formação e as demandas do sistema universitário, a sobrecarga de trabalho e suas consequências, como ausência do lazer, perda de controle sobre o projeto acadêmico e adoecimento. Conclui que a principal contradição vivida pelo docente é a de que a autonomia percebida por ele nãoé a exercida, uma vez que está submetido a diversos controles internos e externos do sistema meritocrático, cujas exigências ultrapassam a capacidade física e psíquica do professor para responder adequadamente. Entretanto, compreender o processo de alienação é a base para a transformação e emancipação daqueles que possuem o papel fundamental de desenvolver as capacidades do outro.

PALAVRAS-CHAVE: alienação, precarização, trabalho docente, universidade, educação superior.
\end{abstract}

\section{O PROCESSO DE PRECARIZAÇÃO E ALIE- NAÇÃO NO TRABALHO}

Vivemos, hoje, um processo contraditório no que diz respeito ao trabalho, expresso na seguinte situação: apesar de as condições de trabalho terem melhorado em parte, e a despeito do fato de também, em parte, ter sido reduzida a distância entre planejamento e execução, aumentando a participação em determinados temas, a subjetividade produzida continua resultante de uma existência inautêntica e estranhada nos termos que coloca Antunes (1999). Segundo esse autor, tais benefícios obtidos pelos trabalhadores têm sido largamente compensados pelo capital, uma vez que o pensar, o agir e o propor dos trabalhadores estão voltados totalmente para os objetivos intrínsecos das empresas. Mais complexificada, a aparência de maior liberdade

* Professora Adjunto do Instituto de Humanidades, Artes e Ciências Prof. Milton Santos da Universidade Federal da Bahia - IHAC/UFBA. Pesquisadora do Centro de Recurso Humanos - CRH/FFCH/UFBA e consultora do Núcleo de Psicologia Social da Bahia.

Estrada de São Lázaro, 197. Federação, Cep: 40.210-730. Salvador, Bahia-Brasil. deniselemos50@hotmail.com no espaço produtivo tem como contrapartida o fato de que as personificações no trabalho devem se converter ainda mais em personificações do capital. Se assim não fizerem, se não demonstrarem aptidões (vontade, disposição, desejo), trabalhadores serão substituídos por outros que demonstrem perfil e atributos para aceitarem esses novos desafios (Antunes, 1999).

Essa contradição vai se configurar como uma dimensão fundamental no processo de precarização do trabalho na contemporaneidade, que é definido por Thebaud-Mony e Druck (2007) como um " Processo social constituído por uma amplificação e institucionalização da instabilidade e da insegurança, expressa nas novas formas de organização do trabalho - onde a terceirização/ subcontratação ocupa um lugar central - e no recuo do papel do Estado como regulador do mercado de trabalho e da proteção social" (apud Druck, 2009, p.10). Segundo as autoras, trata-se de um processo que atinge todos os trabalhadores, independentemente de seu estatuto.

A precarização do trabalho tem aprofundado a alienação, na medida em que instrumentos 
cada vez mais sofisticados têm sido desenvolvidos pelo capital para subordinar o trabalhador, forçando-o a vivenciar uma condição de trabalho deteriorada cotidianamente nas organizações, com um impacto significativo do ponto de vista físico e psíquico.

Dejours (1987) argumenta que, do choque entre um indivíduo dotado de uma história personalizada, de uma identidade, e a organização do trabalho, portadora de uma injunção despersonalizante, em que o desejo do capital se sobrepõe ao desejo do trabalhador, emerge uma vivência de sofrimento psíquico. Para o autor, o comportamento condicionado e o tempo recortado pela organização do trabalho formam uma verdadeira síndrome psicopatológica que o operário, para evitar algo pior, se vê obrigado a reforçar, tornando-se o artesão do seu próprio sofrimento.

O autor considera que a pressão organizacional geradora de um sofrimento psíquico não permite que ele seja revelado em termos de ansiedade ou cansaço, ou qualquer outro sintoma de natureza mental, mas apenas físico, que é o aceitável. Segundo o autor, é só retirar a pressão que o sofrimento desaparecerá. A alienação, no sentido psiquiátrico, é equivalente ao conceito marxista dos manuscritos de 1844, que seria a substituição da vontade própria do sujeito pela do objeto. Nesse sentido, passaria pelas ideologias defensivas, em que o sujeito acabaria por confundir seus desejos próprios com a injunção organizacional que substitui seu livre arbítrio. O indivíduo acabaria por tolerar tudo sem fazer triunfar sua própria vontade. A organização do trabalho seria o veículo da vontade de um outro, a tal ponto poderosa que, no fim, o trabalhador se sente habitado pelo estranho. A alienação seria uma verdade clínica que, no caso do trabalho, toma a forma de um conflito em que o desejo do trabalhador capitulou frente à injunção patronal. Ele argumenta ainda que, se deve haver uma luta por novas relações sociais, ela deveria passar por um processo de desalienação. Pergunta também se a prevalência concedida às mudanças nas relações de produção arrisca a passar por cima da alienação sem transformá-la, e se o desmantelamento dos mecanismos de alienação não é uma condição necessária, mas insuficiente para um projeto de transformação social. Acrescenta:

... que felicidade seria essa, louvada por uma sociedade, que não teria por fundamento (fundamento não objetivo) a libertação da vida mental? Libertação de seu exercício no trabalho e na atividade produtiva?(Dejours, 1987, p.138).

Conclui dizendo que qualquer que seja o regime político considerado, na medida em que pretende superar os obstáculos socioeconômicos à felicidade, deverá ser julgado por sua capacidade de levar em conta a relação conflituosa entre organização do trabalho e o aparelho mental.

\section{AALIENAÇÃO NO ÂMBITO DA EDUCAÇÃO}

Trazendo o debate para o campo da educação, Frigotto (1994) considera que os novos conceitos utilizados - globalização, integração, flexibilidade, competitividade, qualidade total, pedagogia da qualidade e a defesa da educação geral, formação polivalente e "valorização do trabalhador" - constituem uma

imposição das novas formas de sociabilidade capitalista, tanto para estabelecer um novo padrão de acumulação, quanto para definir as formas concretas de integração dentro da nova reorganização da economia mundial (1994, p.41).

O autor argumenta que há uma mudança nos interesses dos homens de negócio em relação à educação e à formação humana, devido "às novas bases que a reconversão tecnológica e redefinição do padrão de acumulação capitalista demandam na reprodução da força de trabalho." (Frigotto, 1994, p.34). Para ele, a redescoberta da dimensão humana é muito mais um sinal de limite do que de auto-negação da forma capitalista de relação humana. Portanto, a valorização da educação básica geral, a "revalorização" da formação geral do trabalhador (desde o ensino 
básico à pós-graduação) como forma de obter trabalhadores com capacidade de abstração, flexíveis, polivalentes e criativos, atende a uma lógica do mercado, caracterizada pela diferenciação, segmentação e exclusão.

Os novos jargões do discurso empresarial de polivalência, flexibilidade, integração e trabalho enriquecido passam a ocupar um espaço significativo em congressos, seminários, encontros, nos mais diversos âmbitos, inclusive de modo crescente nas universidades, que aderiram às ideias da "qualidade total", sem qualificar essa qualidade. Entretanto, a exclusão provocada por esse modelo adotado nas empresas é tão significativa, que se tornou fundamental ir além da apologia da valorização do trabalhador e da sua formação geral e polivalente, buscando o seu efetivo sentido político-prático. Em outras palavras, desvendar qual é a educação que convém ao desenvolvimento empresarial nos tempos atuais.

A consequência, no campo da educação e da formação, é um processo de subordinação que resulta na busca pela delimitação de conteúdos e pela gestão do processo educativo. "No plano dos conteúdos, a educação geral, abstrata, vem demarcada pela exigência da polivalência ou de conhecimentos que permitam a policognição.” (Frigotto, 1994, p.52).

Entretanto, essas exigências vêm permeadas de conflitos e contradições, pois, ao tempo em que se esperam trabalhadores altamente qualificados, inteligentes, flexíveis, com visão global e com uma excelente estrutura emocional, essas mesmas características enfrentam dificuldades de se concretizar quando se deparam com a estreiteza da lógica do mercado e do lucro, transformando-se, nesse sentido, num processo de desqualificação.

\section{O TRABALHO DOCENTE NAS UNIVERSIDA- DES FEDERAIS}

O exame do papel e das atividades desenvolvidas pelo professor universitário, hoje, pode lançar luzes sobre o impacto das transformações operadas no contexto das políticas neoliberais, que implicaram alterações significativas no processo do trabalho e no sistema de gestão das Universidades Federais, a partir da década de 1990, como também pode alimentar o debate sobre a questão da autonomia e da identidade com e no trabalho docente.

Mancebo e Franco (2003) esclarecem que, no processo de flexibilização do trabalho docente, algumas mudanças afetam o docente, gerando uma perda de identidade, pela transfiguração das atividades do ensino e da pesquisa. $\mathrm{O}$ ensino flexibilizado pelos cursos de curta duração, o ensino a distância e o "aligeiramento" de currículos insere-se num processo em que a mercadoria deve ser produzida de forma rápida e de acordo com critérios de eficiência e produtividade. E acrescentam que, nesse contexto, a dimensão interrogativa e crítica do trabalho docente, própria ao espaço universitário, é subtraída, "retirando a formação e a prática profissional, assim como a produção de conhecimento, do campo da política e da ética." (2003, p.34).

$\mathrm{O}$ acesso ao conhecimento sempre obteve importância na luta competitiva, mas, no contexto atual, adquire novas ênfases. As rápidas mudanças de gostos, de necessidades e dos sistemas de produção flexíveis implicam uma corrida para o desenvolvimento da última técnica, para a aquisição da mais recente descoberta, como um fator vital para obter vantagem competitiva. A produção do conhecimento ganha notável expansão, mas um conhecimento técnico, receita para resolução de problemas imediatos. É a transformação do saber em mercadoria-chave.

O termo docência tem sido tradicionalmente usado para expressar o trabalho do professor, mas existe um conjunto de funções que ultrapassam o exercício da docência. As funções formativas convencionais, como ter um bom conhecimento sobre sua matéria e saber explicála, foram se tornando mais complexas. Com o passar dos tempos e com o surgimento de novas condições de trabalho - massificação dos estudantes, divisão de conteúdos, incorporação de 
novas tecnologias, associação do trabalho em sala de aula com o acompanhamento do aprendizado em empresas -, as funções docentes passaram por um processo de ampliação e complexificação. Hoje, oficialmente, as universidades públicas atribuem aos professores quatro funções: o ensino, a pesquisa, a administração e a extensão. A Constituição de 1988 definiu a função das universidades em termos da indissociabilidade entre ensino, pesquisa e extensão, e essa formulação permanece até os dias atuais como objeto de interpretação e debate dentro da comunidade universitária.

\section{A MULTIPLICIDADE DAS ATIVIDADES DO- CENTES}

Botomé (1996) considera que existe uma dificuldade de localizar e definir o que caracteriza a responsabilidade primeira ou maior da instituição universitária, onde convivem exigências diversas, de muitos agentes, com formações variadas, e diante de tarefas voltadas para múltiplos assuntos. Para ele, o professor universitário precisa ser um profissional múltiplo. Precisa ser um técnico e especialista num campo de trabalho, mas também precisa ser competente como pesquisador ou cientista em uma área do conhecimento. Já temos aí duas profissões, mas existem outras exigências: ele precisa ser um profesor de nível superior capaz de ensinar e preparar profissionais, para realizar as tarefas mais complexas da sociedade. E, além disso, precisa estar apto para ser um administrador, pois vai defrontar-se com a necessidade de gerenciar projetos de pesquisa e de ensino, coordenar grupos de trabalho e órgãos da estrutura administrativa universitária, como departamentos, cursos etc. E ainda precisa ser um escritor razoável.

Uma das consequências das múltiplas atividades do professor, dessa polivalência, é a intensificação e a sobrecarga de trabalho, o que, por sua vez, gera a necessidade de trabalhar no tempo de lazer, com consequências em termos de desgaste físico e psíquico, assim como difi- culdades na relação familiar. De acordo com Botomé (1996), as dificuldades permanecem quando, diante de tantas facetas do papel docente, a sua preparação é desigual no atendimento das demandas da vida na universidade. A pósgraduação, que deveria capacitá-lo para ser um professor universitário (mestre de nível superior) e um cientista (doutor em uma área do conhecimento), tem aumentado a sua especialização técnica em um assunto e em técnicas de pesquisa. O resultado é que os professores se preparam mais para a dimensão de especialista e de pesquisador do que em relação às demais exigências (Botomé, 1996). E o autor analisa que:

O profissional desenvolve uma experiência que, com frequência muito grande, não o leva a completar as lacunas em sua formação, mas a desenvolver e fortalecer o que é aceito, o que funciona ou o que lhe dá poder, capacidade de influência no meio social ou institucional. Com isso, consolida-se um poder cada vez maior, que o leva a agir sobre os demais e sobre a instituição, de maneira a consolidar não o que vale a pena a longo prazo, para a instituição e para a sociedade, mas o que o leva a ganhar, sentir-se seguro, obter mais poder, ser aceito e reconhecido (p.29).

E ainda acrescenta, citando Matus (1987), que o experiencialismo com baixo capital intelectual (pouco preparo ou preparo desequilibrado para as múltiplas funções na universidade), leva a consolidar aspectos fortuitos, acidentais e irrelevantes (os mais óbvios e aparentes em geral) das práticas diárias.

Outra ótica sobre essa mesma questão é trazida por Frigotto (2001), quando chama a atenção para as diferentes formas de polivalência, uma vez que existem tipos de atividades polivalentes, que não demandam nenhuma qualificação maior, tratando-se, apenas, de intensificação do trabalho, cuja consequência, na prática, é a desqualificação do trabalhador.

$\mathrm{Na}$ pesquisa de doutorado sobre o trabalho docente na Universidade Federal da Bahia, realizada por Lemos (2007), em que foram analisadas as condições, a organização e as relações interpessoais no trabalho, com o foco nas categorias conceituais da alienação e autonomia no 
trabalho, os professores entrevistados relataram ser praticamente impossível atender a todas as demandas do papel de docente, sendo necessário usar o tempo de lazer, o que resulta em desgaste físico e psíquico e adoecimento

Wernick (2000), num estudo realizado também na UFBA sobre condições de saúde e trabalho mostrou que, devido à condição inadequada das salas de aula e dos móveis, ao risco de violência pessoal e à natureza em si do processo de trabalho (pressão, sobrecarga), dentre outros fatores, os professores trouxeram queixas relativas a cansaço mental $(44,6 \%)$, dor nas pernas $(36,1 \%)$, rinite $(28,1 \%)$, rouquidão $(25,9 \%)$ e esquecimento (25\%). Entre as doenças mais frequentes registradas registram-se: varizes nas pernas ( $25,3 \%$ nas mulheres e $11,3 \%$ nos homens) e hipertensão arterial $(17,1 \%$ nas mulheres e 19,7\% nos homens). A pesquisa também demonstrou uma associação positiva entre as condições gerais de trabalho e a ocorrência de distúrbios psíquicos menores (tensão, cansaço, tristeza, alterações no sono, diminuição de energia, sintomas somáticos), que foram constatados por $18,7 \%$ dos pesquisados. Um dado importante da pesquisa é que os professores que informaram possuir um alto grau de controle de suas atividades e alta demanda de trabalho foram os que mais estavam propensos a adoecer (maior percentual de distúrbios psíquicos menores).

Lipp (2002), ao listar os fatores estressores do professor que atua na pós-graduação, colocou foco nas tarefas administrativas (elaboração de currículos, relatórios, projetos) demandadas pelas agências externas, no excesso de informação recebida, nas demandas tecnológicas e na invasão do trabalho docente no horário de descanso. Segundo a autora, o docente vai fisicamente para casa, mas o trabalho não termina. Segundo ela,

... são teses para ler, projetos para avaliar, relatórios para escrever, e-mails para responder, celulares que tocam em casa, computadores portáteis que acompanham o professor e garantem o seu trabalho no horário de lazer (2002, p.60).
É o trabalho invadindo o espaço pessoal e privado, impedindo que o professor vivencie outras dimensões da vida, descanse, pense e refaça as energias para enfrentar o cotidiano no início da semana.

Francisco de Oliveira (2009), ao analisar a tese de doutorado de Pedro Floriano Ribeiro (2010), que investigou as sete Universidades Federais mais ricas do sudeste brasileiro, sintetiza dizendo que a produtividade decuplicou em número de artigos em revistas indexadas, docentes e pesquisadores, quintuplicou o número de alunos de pós-graduação e duplicou o número de alunos de graduação. Do outro lado, houve uma regressão salarial dos docentes, diminuição da relação funcionário / docente e funcionário /aluno, ocasionando maior exploração do trabalho. Segundo ele, "Dos funcionários e professores entrevistados todos tomam algum tipo de neuroléptico para manter a concentração, alguns não veem os filhos nem pela manhã nem à noite. É o produtivismo aplicado à lógica acadêmica, o grande fracasso da universidade" (Oliveira, 2009, p.48).

\section{A FORMAÇÃO DOCENTE E A QUALIDADE DE ENSINO}

Em função das características estruturais descritas acima, a controvérsia básica da formação docente gira em torno da dupla orientação: ensino e pesquisa. Um maior status tem sido atribuído à pesquisa pela instituição universitária, transformando-a num componente básico da identidade e do reconhecimento do docente universitário. O que tem sido avaliado nos concursos de ingresso e promoção são os méritos das pesquisas, que os professores tendem a priorizar, por causa dos efeitos econômicos e de status no campo acadêmico, uma vez que, o destino prioritário dos investimentos para a formação do pessoal é orientado principalmente para a pesquisa. Isso faz com que, contraditoriamente, a docência transforme-se em uma atividade marginal dos docentes. A partir daí, desenvolve-se a crença de que, para ser um bom profes- 
sor universitário, é necessário ser um bom pesquisador. Pesquisar representa um nível de desenvolvimento intelectual superior, uma capacidade para ver as coisas de forma mais rigorosa e sistemática, um maior conhecimento dos assuntos que transitam no campo científico (Zabalza, 2004).

Entretanto, na prática, o que se observa é a existência, muitas vezes, de excelentes pesquisadores que são professores medíocres, quer pela utilização de uma linguagem complexa e pouco accessível, quer pela dificuldade de relacionamento com os alunos, ou pelas aulas muito centradas no conteúdo, sem preocupação com a forma de comunicação. Inclusive, algumas vezes, não há conexão entre o conteúdo de sala de aula e aquele oriundo da pesquisa.

$\mathrm{Na}$ pesquisa sobre trabalho docente na UFBA, emergiu a percepção de que a distância cultural oriunda de gerações diferentes dos professores e dos alunos seria o motivo de afastamento dos professores mais antigos da graduação, em função do esforço exigido para responder às demandas desses alunos. Alguns professores expressaram sua preocupação pela demanda da "técnica”, do "prático", do "imediato" por parte dos alunos, e da dificuldade de estimulálos para a busca de um conhecimento amplo, crítico e socialmente referenciado (Lemos, 2007).

Carvalho (2009) considera como foco da crise universitária hoje a hegemonia da fragmenquanto a Universidade não empreender a religação da cultura científica com a cultura das humanidades, a crise não se resolverá. Ele pondera: “... não se trata de uma negação das disciplinas tecnocientíficas, mas de sua inserção num contexto mais amplo. É assim que se formam os verdadeiros intelectuais.” (p.50)

\section{A tendência a performatividade e o conceito} de qualidade de ensino

Cowen (1996 apud Leite et al., 2003), ao analisar a contemporaneidade da missão das uni- versidades, descreve a tendência da performatividade. Há uma insistência governamental sobre a ideia de produto, que é cuidadosamente medido por sua performance. A consequência imediata para a cultura universitária é percebida através dos efeitos corrosivos da redefinição dos controles de qualidade e, também, pelo deslocamento das lideranças acadêmicas em direção às necessidades administrativas, observando-se, a partir daí, um enfraquecimento dos recursos financeiros, pedagógicos, humanos e de pesquisa. Segundo o autor, trata-se de um projeto político explícito, estruturado a partir de desafios externos e extranacionais, uma vez que, a universidade é a arena correta para a interligação entre negócios, indústria e Estado.

Segundo Sobrinho (2001), a retórica do conceito de qualidade usado no âmbito educacional é oriunda do Banco Mundial, que opera um deslocamento, associando-a sempre à noção de "eficiência" que, em sua forma ótima, se chama "excelência". Essa "qualidade máxima" deve ser quantificada, avaliada e comparada, estimulando a competição entre as instituições pelos parcos financiamentos. A insistência na "excelência" visa a selecionar os melhores, os mais dotados, para tirá-los do suposto marasmo geral e disponibilizar os melhores meios. $\mathrm{O}$ autor explica:

O preço da excelência de algumas instituições é o desaparecimento de muitas outras, que, embora não preencham aqueles requisitos de competitividade no mercado aberto, certamente, cumprem relevantes funções, cuja qualidade deve ser avaliada, por outros critérios, que assegurem um desenvolvimento social mais igualitário, e, em que a excelência não seja um privilégio de poucos e a exclusão de muitos (Sobrinho, 2001, p.164).

Quando, então, se fala em um "novo perfil" que oriente um programa de formação docente emerge o modelo de competência, amplamente na "moda" nas empresas hoje. E quando se examina que "competências" seriam essas, surgem características voltadas para a personalidade do profissional, tal como propõe Masetto (2003): adaptabilidade ao novo, criatividade, autonomia, 
comunicação, iniciativa e cooperação. Segundo o autor, "profissionais intercambiáveis, que combinem imaginação com ação".

Esse modelo proposto, aliado à racionalidade da meritocracia, termina por se constituir numa outra "moda empresarial", que é o empreendedorismo, intimamente relacionado com a questão da empregabilidade, o qual mascara a realidade do projeto neoliberal de enxugamento das empresas e demissão em massa, atribuindo às pessoas a responsabilidade pelo seu desemprego, em última instância.

Parece, então, ser esse o perfil adequado para adaptar o professor ao processo de flexibilização do trabalho, no qual as Universidades públicas, à medida que são privatizadas por dentro e, concomitantemente, adotam o modelo da produtividade e da rentabilidade empresarial, também demandam professores flexíveis, capazes de se adaptar rapidamente aos cursos-relâmpago, a avaliações quantitativas por produção, a prazos reduzidos e a resultados de aplicação imediata. Essa visão pode ser claramente deduzida, por exemplo, em algumas linhas de ação propostas por Masetto (2003): formação profissional simultânea com a formação acadêmica, por meio de um currículo dinâmico e flexível, que integre teoria e prática; desestabilização dos currículos fechados, acabados e prontos.

Outra dimensão é trazida por Sobrinho (2001), quando considera que essa concepção de Universidade, medida pela sua eficiência em corresponder às demandas do mercado, opera um estreitamento da função pública, uma vez que a função política é neutralizada pela função econômica. A Universidade é vista como uma instituição que deve dar respostas objetivas, técnicas, eficientes a uma sociedade modelada pela tecnologia. Citando Morin (1994, p.90) e Petrella (1994, p.10), o autor considera que à tecnologização da epistemologia, nos termos de Morin, correspondem o sobredesenvolvimento da especialização, o predomínio do técnico sobre o político, a desqualificação do cidadão pelo especialista. A tecnologia torna-se cada vez mais incontrolável e constitui-se como o mais importante indicador do progresso da sociedade. $\mathrm{O}$ autor salienta que não se trata da negação da tecnologia, mas da necessidade de sua politização, ou seja, trazê-la para o campo do debate público, da cidadania.

Segundo Bianchi e Braga (2009), os critérios de eficácia quantitativa e monetária são adequados para orientar a aquisição de fortunas, mas apresentam graves problemas quando aplicados à produção de conhecimento e às atividades de pesquisa e ensino. Os autores exemplificam com a aprovação da lei de inovação tecnológica, em 2005, pelo governo Lula. Segundo eles,

... essa lei coroou o processo pelo qual o poder da acumulação capitalista sob domínio das finanças e a consequente pressão sobre o sistema nacional de produção e difusão do conhecimento científico aprofundaram a alienação das atividades acadêmicas (2009, p.54).

\section{A percepção do aluno}

Por outro lado, o aluno também está submetido a essa complexa teia de tensões e contradições e encontra dificuldades de compreender e ser compreendido pelo docente. Suas principais percepções:

... o professor sabe muito, mas não sabe ensinar, o professor é um profissional competente em sua área, mas dá aula para ele mesmo, o professor reclama que ganha muito pouco e, por isso, não se dedica ao magistério como deveria, o professor não se dedica só à sala de aula, então, falta, negligencia e comenta, frequentemente, que tem coisas mais importantes para fazer, o professor é autoritário tanto na ação docente quanto na avaliação (Leite et al., 2003, p.62).

Configura-se, assim, uma dupla pressão, caracterizada, de um lado, pelas demandas institucionais que dirigem o professor muito mais para a pesquisa do que para o ensino, pela crença de que, se ele é um bom profissional ou possui títulos, está apto para ensinar; por outro lado, os alunos são oriundos de cursos de nível médio cada vez mais pragmáticos, direcionados para o vesti- 
bular, pautados em receitas rápidas e prontas. Essa situação gera um choque de perspectivas e valores que transforma a relação ensino - aprendizagem numa tensão e num confronto permanente entre professores e alunos, redundando, em algumas situações, num "pacto de mediocridade, onde o professor finge que ensina e o aluno, o interessado no diploma, finge que aprende".

Vasconcelos (2003) investigou a opinião de alunos de pós-graduação de um curso de Metodologia do Ensino Superior no período de 1990 a 1995, com uma amostragem de 200 alunos. Era um grupo bastante heterogêneo em termos de formação e de interesses: alguns já eram professores e, portanto, consideravam-se suficientemente treinados para tal; outros não pretendiam exercer a docência a princípio; e outros eram bastante motivados a obter ou melhorar os conhecimentos na área. Embora o curso tenha alcançado 86\% de satisfação dos alunos, com relação às suas expectativas, foram feitas as seguintes críticas e sugestões: aumento da carga horária, utilização de maior quantidade de técnicas ao longo da disciplina, o que foi interpretado pela pesquisadora como "receitas prontas de como dar aula", necessidade de apostila do curso. Por outro lado, consideraram enriquecedora a oportunidade de poder repensar a própria prática.

O professor universitário encontra-se, então, no centro de contradições: é consagrado pelo diploma de mestre, mas, na prática, é questionado em relação à sua competência de ensinar; é formado em pesquisa, mas tem de captar recursos para pesquisar, o que demanda tempo para atender a uma burocracia administrativa que termina interferindo na própria pesquisa; é demandado em termos de mudança na forma de ensinar pelos alunos, e a sua progressão funcional e status profissional dependem primordialmente do número de publicações e outras atividades que não incluem o resultado efetivo na sala de aula.

Parece claro que a formação docente voltada para um redimensionamento dos conteúdos, da metodologia e relação entre professor e aluno é necessária, mas não é suficiente, uma vez que, como vimos, existe uma organização do trabalho sistêmica que transcende o comportamento em sala de aula e o perfil do professor, condicionando a sua ação.

Cunha (1998) realizou um estudo, em 1989, sobre o professor universitário considerado bom pelos alunos. Esses professores desenvolvem um grande número de habilidades de ensino: fazer perguntas, variar estímulos, organizar o contexto das aulas, apresentar muitas qualidades humanas e afetivas no trato com os alunos e com o conteúdo do ensino. Entretanto, esses professores ainda trabalham na perspectiva reprodutiva do conhecimento, e essa é uma posição aceita pelos alunos. Os professores são capazes de apresentar o melhor conteúdo, a ser desenvolvido em sala de aula, mas não conhecem procedimentos sobre como fazer o aluno chegar ao mapeamento próprio da aprendizagem. O bom professor relata os resultados de suas pesquisas, mas pouco estimula o aluno a fazer as suas próprias.

Os professores objeto desse estudo consideraram ter sido a sua história como alunos o que mais influenciou na repetição de atitudes consideradas positivas ou no esforço de fazer exatamente o contrário do que faziam seus professores que foram avaliados negativamente.

\section{O PROFESSOR EMPREENDEDOR: a capta- ção interna e externa de recursos}

Além do ensino, da pesquisa e da extensão, na visão de Zabalza (2004), atualmente, novas funções são agregadas ao trabalho do docente, as quais tornam o exercício profissional mais complexo. Trata-se do "business", ou seja, a busca de financiamento, a negociação de projetos e convênios com empresas e instituições, as assessorias, a participação como especialista em diversas instâncias científicas, além das "relações institucionais" com outras Universidades, empresas e instituições, buscando reforçar o caráter teórico e prático da formação e, em alguns 
casos, seu caráter internacional.

A quantidade de formulários a serem preenchidos para obtenção de recursos assim como aqueles que são necessários para a prestação de contas, dentro de prazos exíguos, constitui uma dimensão que emerge com o papel do professor de "captador interno de recursos" ao sistema educacional do governo, mas externo à Universidade. Implica a agregação de uma série de atividades administrativas ao trabalho docente, para as quais o professor não conta com apoio em termos de recursos humanos por parte da Universidade, causando um excessivo envolvimento com atividades-meio que, muitas vezes, concorrem com o desenvolvimento da pesquisa e do ensino em si mesmos.

O papel de "captador de recursos" externos à Universidade e ao sistema educacional do governo, pode, por um lado, resultar na possibilidade de desenvolvimento de um relevante projeto de pesquisa e extensão acadêmica, mas, por outro, significar uma distorção dos objetivos essenciais da instituição, um processo de privatização por dentro da Universidade pública. E aí pode se estabelecer uma contradição: ao mesmo tempo em que a Universidade precisa relacionar-se com os diversos setores da sociedade, essa mesma relação pode significar um processo de alienação institucional.

Americano da Costa (1999) chama atenção para o fato de que algumas dessas iniciativas, como a cobrança por atividades desenvolvidas pela Universidade, já estão ferindo o princípio constitucional da gratuidade do ensino (Art. 205-IV), ratificado pela LDB (Art.3-VI), restrito agora, para cursos acadêmicos de graduação e pós-graduação (mestrado e doutorado). Além disso, fica instituída a cobrança geral pela prestação de serviços via fundações privadas.

Segundo a autora, na medida em que critérios e objetivos, padrões e prazos são definidos pelos clientes e não pelos pesquisadores, a autonomia universitária se transforma em heteronomia. E acrescenta que as consequências são:
... a quebra do princípio constitucional de gratuidade do ensino nos estabelecimentos oficiais, a quebra do princípio da isonomia salarial e a perda da autonomia universitária, pelo atrelamento das suas atividades à lógica do mercado e aos interesses privados.

A Universidade, como instituição produtora de conhecimento a ser disponibilizado socialmente, necessita relacionar-se com os diversos agentes sociais, inclusive as empresas, desde que as pesquisas encomendadas sejam submetidas a uma avaliação ética em termos do objeto, com controle do processo e dos resultados. É importante assinalar que, mesmo nos convênios com instituições públicas, nos quais o beneficiário é a maioria da população, na relação com os agentes do Estado, a questão da autonomia da gestão do processo e a utilização dos resultados são dimensões a serem analisadas, tendo em perspectiva os objetivos essenciais da Universidade e as necessidades da população.

Filgueiras (1998) considera que existe uma necessidade cada vez mais intensa de as universidades se relacionarem com os segmentos econômicos e sociais. Entretanto, chama a atenção para as diferentes naturezas das duas instituições; de um lado, as empresas, que buscam resultados imediatos, essenciais para se manterem no mercado; do outro, as universidades que, por características intrínsecas do trabalho didático-científico, exigem uma dinâmica distinta. A natureza do trabalho intelectual exige amadurecimento e debates, o que contrasta com os prazos curtos e rígidos das empresas. Outras exigências estão relacionadas com a difusão dos resultados para a comunidade acadêmica e o controle social dos recursos envolvidos, o que pode envolver questões éticas sobre a autonomia da produção do conhecimento e a administração do recurso público.

Sobrinho (2001) considera que, quando a universidade se aproxima demasiadamente das empresas, pode terminar se confundido com elas, ao passo que, se mantém uma distância crítica, os significados concretos e a relação adquirem consistência, e "a universidade crítica preserva sua identidade e autonomia” (p.167). 
A maioria dos professores entrevistados na pesquisa realizada na UFBA concorda com as pesquisas encomendadas por instituições públicas ou privadas, desde que sejam submetidas a uma avaliação ética. Um professor opinou que o que existe é pouco, que deveriam existir mais encomendas, motivadas pela necessidade de resolver problemas sociais concretos. Alguns professores foram radicalmente contra esse tipo de visão, considerando que quem paga define a direção do trabalho. Outra percepção é que o problema central reside em saber quem vai se apropriar dos resultados do trabalho dessa pesquisa, na sociedade e no interior da universidade, assim como indagar sobre a origem dos recursos que irão financiar o estudo (Lemos, 2007).

A existência de uma regulamentação da universidade, que defina princípios compatíveis com as suas características essenciais, com os seus objetivos centrais de formação e geração de conhecimento, poderia ser útil no sentido de reduzir a desigualdade entre as unidades, em termos das condições de trabalho, devido não só às diferentes capacidades de captação de recursos, como também devido às diferentes óticas e posicionamentos ideológicos. Assim como pode ser igualmente útil que cada área do conhecimento ou cada departamento possam clarear o que seria a sua "referência social" para a definição dos conteúdos do ensino e dos temas de pesquisa (2007).

\section{AAUTONOMIA NO TRABALHO: as diversas óticas e dimensões \\ A complexa teia de determinações}

Existe um conjunto de diferentes níveis da gestão do ensino superior que terminam por afetar o cotidiano do professor, significando também um conjunto permanente de tensões institucionais. Nesse sentido, consideramos que, tendo como pano de fundo o Plano Diretor da Reforma do Estado, a Reforma Administrativa e
Previdenciária e a política para as Instituições Federais de Ensino Superior, a série de instrumentos legais (LDB, decretos e portarias) tem aumentado o poder de intervenção do Estado na vida universitária, como, por exemplo, na escolha de dirigentes, na política de avaliação (ENADE), na nova sistemática de avaliação da pós-graduação (CAPES), na nova regulamentação do FIES, na formulação de novas diretrizes curriculares, no contingenciamento, congelamento e liberação de recursos, na definição da política salarial e de vagas de docentes e discentes.

Essas medidas atingem, de forma significativa, o elemento central definidor do ensino superior, que é a autonomia docente, ao mesmo tempo em que colocam os professores como receptáculo de uma forte pressão, definida por uma burocracia estatal e institucional, dirigida por uma racionalidade estranha (a da produtividade) em relação às características intrínsecas do fazer universitário, cuja função fundamental é construir coletivamente o conhecimento, tornálo acessível à população e formar pessoas que possam assumir uma postura crítica e criativa diante dos desafios da realidade.

Como essa teia complexa de medidas e sua motivação política não são visíveis para o conjunto da sociedade, a dimensão que é possível acessar, além da degradação física, é a concepção de que a crise pela qual passa a Universidade é determinada pelo baixo desempenho dos professores, sua falta de comprometimento com a instituição universitária e o excesso de liberdade de atuação. A partir dessa linha de raciocínio, o professor vai se caracterizando como o depositário, o "bode expiatório" das mazelas do sistema e, ao reagir às estratégias de avaliação e controle, é rotulado de corporativista. Esse é o embate ideológico posto pela hegemonia do pensamento neoliberal, que busca desqualificar tudo que é "público", especialmente os funcionários. Chauí (2001) questiona essa visão e indaga se o que se chama de corporativismo não seria uma reação legítima de um grupo profissional que, na ausência de leis que protejam seus direitos, 
vêm-se na obrigação de se articular e assumir esse papel.

\section{O processo de controle do desempenho aca- dêmico do docente}

A questão do financiamento interno e externo é uma forma importante de controle da produção do trabalho docente, mas ainda existem outros mecanismos acionados por órgãos acadêmicos, que visam a outro tipo de controle: o do desempenho acadêmico. Do ponto de vista da estrutura do Estado, três órgãos interferem mais diretamente na gestão das IFES (Instituições Federais do Ensino Superior): a SESU (Secretaria de Ensino Superior) do MEC (Ministério de Educação e Cultura), o CNE (Conselho Nacional de Educação) e o INEP (Instituto Nacional de Estudos Pedagógicos). Cabe à SESU a formulação de políticas que, quase sempre, são referendadas pelo Ministro, sendo que, nos últimos anos, sua atividade se expandiu, passando a produzir decretos e portarias que direcionam os rumos do ensino superior, como, por exemplo, o credenciamento de instituições, a autorização e o reconhecimento de cursos, sendo responsável, consequentemente, pelo estabelecimento do padrão de qualidade a que as IFES devem atender. Por outro lado, o orçamento das IFES é também submetido à SESU, o que origina pressões por aumento de recursos, situação que a SESU não tem competência para resolver, uma vez que depende das decisões da área econômica. Outro órgão importante na condução da política do ensino superior é o INEP, cuja função historicamente era a de desenvolver pesquisas e reflexões sobre a educação e teve seu papel cada vez mais ampliado, no sentido de produzir de dados, realizar censos dos diversos níveis educacionais, inclusive criando novos mecanismos de avaliação, a exemplo do ENEM e do ENADE. O CNE é um órgão que funciona de forma autônoma, podendo criar políticas para o ensino, embora dependa da chancela do Ministro (Soares, 2002).
Se a essa estrutura acrescentarmos o Ministério da Fazenda, o do Planejamento e a Casa Civil (Órgãos participantes da elaboração do Projeto de Lei da reforma universitária), verificamos a existência de uma complexa teia de relações institucionais, uma superestrutura de gestão, do ensino superior, em especial das IFES. A consequência é um aumento do controle, que se torna cada vez mais efetivo, como é possível vislumbrar na "ampliação" das funções da SESU e do INEP, que passam progressivamente a exercer um papel controlador no geral, e, especificamente, no nível didático-científico. Todo esse aparato estrutural termina por gerar uma sobrecarga de demandas para a instituição e para o docente.

Uma das consequências dessa superestrutura de controle é a perda progressiva da autonomia docente sobre o seu objeto de trabalho, sobre o fazer acadêmico. A entrada (ENEM) e a saída (ENADE) dos alunos da graduação são avaliadas por instâncias extrínsecas à universidade. As diretrizes curriculares também são definidas externamente. Os programas de pós-graduação obedecem a uma avaliação de desempenho que os classifica de acordo com o mérito obtido. Os pesquisadores também são classificados de acordo com a sua produtividade científica, medida a partir de critérios definidos extrinsecamente. E, mais recentemente, foi criado o SINAES (Sistema Nacional de Avaliação do Ensino Superior) e a CONAES (Comissão Nacional de Avaliação do Ensino Superior). Assim, a autonomia relativa do docente vai cada vez mais se restringindo e até se transformando numa "ilusão de autonomia” (Lemos, 2007).

Outra consequência é a que aponta Botomé (1996), quando considera que, como não há clareza em relação aos objetivos institucionais, o risco seria de transformar a instituição num "escritório de despachantes”, onde predominariam rotinas, normas, formulários, pedidos e programas (destacando-se os de fomento e outros governamentais). Esse predomínio facilitaria o exercício de conveniências políticas ou pessoais de grupos e indivíduos, principalmente se estive- 
rem no governo, na direção ou na administração da instituição. Nesse sentido, todo o esforço e energia que deveriam estar direcionados para os objetivos finais da instituição do ensino superior estariam sendo desviados e perdidos nessas atividades burocráticas, que terminam por cumprir o papel de impedir que processos mais autônomos e emancipatórios se desenvolvam, uma vez que o professor dedica parcela significativa de seu tempo a preencher formulários, a apresentar projetos e propostas demandados pelas diversas instâncias administrativas.

Segundo Botomé (1992), essa dinâmica do poder, em que alguns grupos se apossam de temas e recursos, pode, também, ser gerada pela política de financiar centros de excelência, o que tende a significar uma estratégia de cooptação de algumas instituições em detrimento da emancipação do sistema universitário como um todo. Trata-se de uma estratégia de poder do Estado. A autonomia não é algo estático, absoluto, que alguém concede a outro: é uma forma de relacionamento. Para o autor, esse relacionamento tem sido dificultado pela falta de clareza do contrato social da universidade com o país. O autor defende que a autonomia deve ser conquistada pela "afirmação" da identidade, o que é diferente da ênfase na “defesa pela força”. Ele considera que concorrer, ou disputar as verbas liberadas por projetos do Governo, traduz-se numa busca de autonomia por cooptação e não por emancipação do sistema universitário, o que se daria através de recursos liberados em função de planos e orçamentos anuais.

Mancebo e Franco (2003) argumentam que o governo estimula uma dinâmica de "competição administrada”, na qual é conveniente que departamentos e institutos concorram entre si pelas verbas e pelo sucesso, “o que significa professores e estudantes disputando as bolsas, as migalhas, as vagas nas salas das instituições públicas”. Segundo as autoras, a competição é o motor do desempenho coletivo, e convém, de certo modo, "que todos sejam mal aquinhoados, para sentirem, na devida medida, a importância da disputa" (p.194).

O processo da autonomia docente vai se configurando como a principal contradição vivida no contexto das universidades federais, a partir da percepção dos professores, que a consideram como a dimensão mais importante do trabalho docente, o que justifica, muitas vezes, a sua opção profissional. Essa contradição é expressa de diversas formas: se, de um lado, a autonomia é valorizada como o aspecto mais fundamental na motivação para o trabalho, de outro, essa mesma autonomia gera um não-cumprimento, por parte de alguns, das regras coletivas que, por sua vez, também não estão claras, sendo necessária, nesse caso, uma "autonomização”, uma individualização. Se a autonomia implica em liberdade na definição do conteúdo do trabalho, esse mesmo exercício isola e impede de conhecer o trabalho do outro, o que gera, possivelmente, conflitos de saber e poder, com alienação do processo coletivo.

Bianchi e Braga (2009), ao considerarem que a perda da autonomia docente é crescente, comparam o trabalho docente com o do homem taylorizado, cujo objetivo máximo era reproduzir, de modo automático, um conjunto muito simples de movimentos no menor tempo possível. Na "distopia da universidade neoliberal, o pesquisador deve se submeter a um conjunto determinado de rotinas intelectuais no menor tempo possível”. Se, num caso, empilha-se carvão, no outro, produzem-se papers (p.55).

Nesse sentido, existe um nível geral de desinformação do sindicato que representa a grande maioria dos professores das IFES e pela própria universidade ${ }^{1}$ a respeito do que tem sido produzido, em termos de análises e propostas, para o sistema universitário e para o trabalho docente. Dessa forma, o núcleo central e invisí-

\footnotetext{
${ }^{1}$ Por exemplo, foi possível constatar o desconhecimento do sistema de avaliação institucional PAIUB, de características emancipadoras, por quase todos os professores entrevistados. Um sistema que, se fosse implantado, poderia representar uma importante contribuição para a elaboração de um projeto acadêmico construído coletivamente e um avanço na luta pela autonomia universitária, por se constituir numa proposta que traduzia os princípios mais essenciais da democracia interna.
} 
vel da contradição é o fato de que o grau de autonomia percebido pelos professores não corresponde ao grau de autonomia existente, quando se consideram todos os âmbitos da vida institucional, ou seja, a autonomia percebida não é a autonomia exercida.

Bourdieu e Passeron (1995) argumentam que o poder de violência simbólica, especificamente no seu efeito também simbólico, só pode acontecer na medida em que o poder arbitrário responsável pela imposição de valores jamais aparece em sua completa verdade, ou seja, na medida em que a arbitrariedade cultural do conteúdo que está sendo inculcado não é totalmente revelada, não há transparência. O desconhecimento da verdade objetiva do poder é exatamente sua condição de exercício. O poder arbitrário, de imposição, só pelo fato de ser ignorado como tal, faz-se objetivamente reconhecido como autoridade legítima, o que termina por reforçá-lo.

Para os autores, os exames e os mecanismos de avaliação são as expressões mais visíveis das opções implícitas do sistema de educação, na medida em que impóem como digna uma definição de saber que oferece um dos instrumentos mais eficazes para o processo de inculcação dos valores da cultura dominante. A partir dessa perspectiva, os docentes não são concebidos como sujeitos centrais no desenvolvimento de propostas, com capacidade e direito de participação, mas são agentes de um modelo a implementar, ou, quando são, terminam por constituir uma elite no processo de cooptação para defender o modelo instituído. Segundo Saforcada (2006), se o conceito de autonomia se refere à autogestão e ao autogoverno, fica difícil pensar como ela poderia ser exercida sem sujeitos.

Fávero (2000) observa que a autonomia é um direito educacional, um princípio inerente à atividade universitária, e não à ordem jurídica. "Assim entendida, a autonomia é causa primária da atividade universitária”. A partir dessa perspectiva, a autora considera que existem três tipos de autonomia:
A autonomia didático-científica implica em estabelecer seus objetivos, organizando o ensino, a pesquisa e a extensão; criar organizar e extinguir cursos; elaborar o calendário escolar; fixar normas e seleção, admissão e promoção, outorgar títulos acadêmicos. Do ponto de vista administrativo, significa a liberdade para organizar-se, estabelecer seu quadro de pessoal em articulação com o ministério. No que tange à autonomia de gestão financeira e patrimonial, significa que a instituição tem competência para propor e executar seu orçamento, receber recursos para pagamento de pessoal, despesas de capital e de outros custeios, gerir seu patrimônio, receber doações, subvenções, bem como realizar operações de crédito ou de financiamento com a aprovação do poder público competente (2000, p.62).

Entretanto, Chauí (2001), examinando a relação da universidade com outros sistemas, conclui ser ela uma instituição "completamente" heterônoma em suas diversas dimensões: a econômica (orçamentos, bolsas, financiamentos de pesquisa), a educacional (currículos, programas, sistemas de créditos, formas de avaliação, revalidação de títulos e diplomas, credenciamento de cursos de pós-graduação, critérios para fixar a graduação e a pós-graduação, julgamento de currículos e títulos, a carreira docente etc.), a social e política (professores, servidores e estudantes não decidem quanto aos serviços que desejam prestar nem a quem). E Fantinatti (1998) acrescenta que a aparente autonomia constituirse-ia numa ilusão, numa contradição. A sensação de autonomia e controle sobre o trabalho seria então um fetiche.

A percepção dos professores sobre a sua autonomia no trabalho, na pesquisa realizada na UFBA, de uma forma geral, é restrita ao cotidiano do trabalho, à sala de aula, ao fato de não existir um chefe imediato, excluindo a consideração sobre o controle exercido pelos outros âmbitos de determinação institucional. A grande maioria dos professores entrevistados desconhece o processo progressivo de perda da autonomia da universidade no âmbito financeiro, assim como também não foi possível, para eles, perceber a progressiva introdução de mecanismos de avaliação e de controle pelo Estado, principalmente, na década de 90. Muitos desconhe- 
cem, inclusive, a natureza desses mecanismos, enquanto que outros os percebem como legítimos, necessários, e desconhecem as propostas emancipadoras geradas dentro da própria instituição. Há também os que legitimam a busca de recursos na iniciativa privada como alternativa de financiamento da universidade.

Em síntese, há um nível geral de desinformação sobre aquilo que tem sido produzido, tanto pelo sindicato, que representa a grande maioria dos professores das IFES, quanto pela própria universidade, em termos de análises e propostas para o sistema universitário e para o trabalho docente. Dessa forma, a contradição invisível é o fato de que o grau de autonomia percebido pelos professores não corresponde ao grau de autonomia existente, quando se consideram todos os âmbitos da vida institucional, ou seja, a autonomia percebida pelo professor é muito maior do que a autonomia que, de fato, é possível exercer.

\section{CONSIDERAÇÕES FINAIS}

O professor, dentro desse processo, vai ficando progressivamente imprensado por uma superposição de tensões, contradições e controles institucionais que chegam até o cotidiano do seu trabalho. Ele reage a esse supercontrole isolando-se, reproduzindo o modelo autoritário, inserindo-se na corrida pela titulação e publicação, competindo com os pares, enfim, criticando algumas dimensões, mas lutando, dirigindo suas energias na busca da sua inserção no modelo proposto. Essas contradições se superpõem da seguinte maneira: a carreira não o desenvolve como professor, e sim como pesquisador; para pesquisar, precisa acionar a habilidade de captador de recursos, para a qual não foi habilitado; quando consegue recursos externos, corre o risco de ser visto como possuidor de uma "vida dupla”; se não consegue recursos, sente-se desprestigiado e revoltado, por possuir uma alta qualificação profissional e um retorno salarial incompatível com o seu grau de conhecimento.
Na medida em que o Estado orienta a carreira para a pesquisa (através de recursos e recompensas), transforma o ensino em algo menos importante, até mesmo aversivo para alguns professores. Quando estimula a competição, através do financiamento individual externo e do sistema meritocrático, gera o esgarçamento do vínculo social e conflitos interpessoais, criando, muitas vezes, um clima de trabalho desfavorável à integração do conhecimento. Ao cooptar uma parcela dos professores (os "excelentes", nota 7), o Estado fragiliza a organização coletiva e descaracteriza o papel político do professor, que passivamente assume o papel de "observador crítico"; quando intensifica o trabalho com demandas periféricas à docência, deixa-o sem tempo para o lazer e para a vida cultural, constituindo, assim, uma organização do trabalho que facilita o adoecimento e a alienação.

Mészaros (2005, p.166), pensando a "educação para além do capital", argumenta que o processo histórico muda pela ação de seres humanos, uma vez que nenhum poder dominante pode transformar a diversidade e a complexidade de visões num todo homogêneo e inerte. E reafirma a necessidade de "um processo de contra internalização que não se restrinja à negação, mas que proponha uma alternativa abrangente, concretamente sustentável ao que existe".

Cabe, portanto, aos núcleos críticos das universidades a tarefa de construção de uma rede que possa assumir uma práxis de resgate dos valores fundamentais do processo educativo emancipador que definem uma instituição como universidade.

(Recebido para publicação em 23 de novembro de 2010) (Aceito em 11 de fevereiro de 2011)

\section{REFERÊNCIAS}

ANTUNES,R. Os sentidos do trabalho. São Paulo: Boitempo Editorial,1999.

AMERICANO DA COSTA, N. M. A. da. Reflexões e propostas: universidade com autonomia. Proposta elaborada para 
a postulação ao cargo de Reitora da UFBA. Salvador, 2002. BAlZAN, N. C; SOBRINHO, J. D. (Org.) Avaliação institucional: teoria e experiências. São Paulo: Cortez, 1995.

BIANCHI, Alvaro; BRAGA, Ruy. Um conto de duas universidades - quando a lógica mercantil se sobrepõe à construção do pensamento crítico e reflexivo. Revista CULT, São Paulo, n.138, 2009.

BOTOMÉ, S. P. Autonomia universitária: cooptação ou emancipação. Revista Universidade e Sociedade, Brasília, ANDES, v.2, n.3, jun. 1992.

. Pesquisa alienada e ensino alienante. Rio de Janeiro: Vozes, 1996

BOURDIEU, P.; PASSERON, J. C. La reproducción. México: Fontamara, 1995.

CARVALHO, Edgard. Universidade em debate - democratização ou massificação. Entrevista concedido à Revista CULT, São Paulo, n.138, 2009.

CUNHA, M. I. O professor universitário na transição de paradigmas. São Paulo: JM Editora, 1998.

DEJOURS, C. A loucura do trabalho - estudo de psicopatologia do trabalho. São Paulo: Cortez,1987.

DRUCK, M. da G. Principais indicadores de precarização social do trabalho no Brasil. In: CONGRESSO BRASILEIRO DE SOCIOLOGIA, 14, 2009. Rio de Janeiro. Anais .. Rio de Janeiro: 2009.

FANTINATTI, M. M. C. M. Sindicalismo de classe média e meritocracia: o movimento docente na Universidade pública. 1998. Dissertacão (Mestrado) - Departamento de Sociologia do Instituto de Filosofia e Ciências Humanas da Universidade de Campinas, 1998.

FÁVERO, M de L. Autonomia universitária mais uma vez: subsídios para o debate. In: SGUISSARDI, V. Educação superior: velhos e novos desafios. São Paulo: Xamã, 2000.

FILGUEIRAS, L. Faculdade e indústria, parceria possível e necessária. Gazeta Mercantil, 10 jun. 1998. p.2.

FREIRE, P. Pedagogia da autonomia: saberes necessários à prática educativa. 12.ed. São Paulo: Paz e Terra, 1999.

FRIGOTTO, G. Educação e formação humana: ajuste neoconservador e alternativa democrática. In: GENTILI, P; SILVA, T. T. Neoliberalismo, qualidade total e educação visões críticas. Petrópolis: Vozes, 1994.

LEITE, D; BRAGA, A M; FERNANDES, C. et al. A avaliação institucional e os desafios da formação do docente na universidade pós-moderna. In: MASETTO (Org.) Docência na universidade. São Paulo: Papirus, 2003.

LEMOS, D.V.S. Alienação no trabalho docente: o professor no centro das contradições. 2007. Tese (Doutorado em Ciências Sociais) - Programa de Pós-Graduação em Ciências Sociais da Universidade Federal da Bahia, 2007.

LIPP, M. E. N. O stress do professor de pós-graduação. In: . O stress do professor. Campinas: Papirus, 2002.

MANCEBO, D.; FRANCO, M. E. D. P. Trabalho docente: uma análise das práticas intelectuais em tempos de globalização. In: DOURADO, L. F.; CATANI, M.; OLIVEIRA, J. F. (Org.) Políticas e gestão da educação superior. Goiânia: Alternativa, 2003.

MASETTO, M. (Org.) Docência na universidade. São Paulo: Papirus, 2003.

MÉSZÁROS, I. A educação para além do capital. São Paulo: Boitempo Editorial, 2005 .

MORIN, E. A noção de sujeito. In: SCHNITMAN, D. F. Novos paradigmas, cultura e subjetividade. Porto Alegre: Artes Médicas, 1996.

OLIVEIRA, Francisco. Universidade em debate: democratização ou massificacão. Entrevista concedida a Revista CULT. São Paulo, n.138, 2009.

SAFORCADA, F. Los docentes en las propuestas de autonomia escolar de los 90: los organismos internacionales y el Estado argentino. In: SEMINARIO DA REDE ESTRADO, 6, 2006, Rio de Janeiro. Anais... Rio de Janeiro: UERJ, 2006

SOARES, M. S. A. Os principais atores da educação superior no Brasil. In: SOARES, M. S. A. Educação superior no Brasil. Brasília: CAPES, 2002.

SOBRINHO, J. D. Concepções de universidade e de avaliacão institucional. In: TRINDADE, H. Universidade em ruínas - na república dos professores. Petrópolis: Vozes, 2001.

VASCONCELOS, M. L. Contribuindo para a formação de professores universitários: relato de experiências. In: MASETTO, M. (Org.) Docência na universidade. São Paulo: Papirus, 2003

WERNICK, R. Condições de saúde e trabalho dos docentes da Universidade Federal da Bahia 2000. Dissertacão (Mestrado) - Instituto de Saúde Coletiva, Universidade Federal da Bahia. Salvador, 2000.

ZABALZA, M. A. O ensino universitário - seu cenário e seus protagonistas. Porto Alegre: Artmed, 2004. 


\section{TEACHING JOBS IN FEDERAL UNIVERSITIES: tensions and contradictions}

\section{Denise Lemos}

This paper examines the teaching work in public universities, especially at the Federal University of Bahia - in Portuguese, UFBA, between 2005 and 2008, from the phenomenon of the precarization of labor and the consequent alienation of the worker, based on the results of doctoral research in UFBA. It describes the fundamental dimensions of this process: the multiplicity of tasks, , internal and external fundraising for research, contradictions between training and the demands of the university system, work overload and its consequences, such as absence of leisure, loss of control over the academic project and illness. It concludes that the main contradiction experienced by the teachers is that the autonomy perceived by them is not the one exercised, since it is subjected to various internal and external controls of the meritocratic system, whose demands exceed the physical and psychic capacity of the teacher to respond appropriately . However, understanding the process of alienation is the basis for transformation and emancipation of those who have a fundamental role in developing the capacities of others.

KEYworDS: alienation, precarization, teaching, university and higher education.

\section{L'ENSEIGNEMENT DANS LES UNIVERSITÉS FÉDÉRALES: tensions et contradictions}

\section{Denise Lemos}

Cet article présente le travail des professeurs dans les Universités Fédérales et tout spécialement au sein de l'Université Fédérale de Bahia, entre 2005 et 2008. On y analyse le phénomène de précarisation sociale du travail et, par conséquent, d'aliénation des travailleurs à partir des donnés de la recherche de doctorat réalisée à UFBA. On y décrit les dimensions fondamentales de ce processus: la multiplicité des tâches, la demande de fonds internes et externes pour la recherche, les contradictions entre la formation et les exigences du système universitaire, la surcharge de travail et ses conséquences tels que l'absence de loisirs, la perte de contrôle du projet académique et le fait de tomber malade. On en arrive à la conclusion que la principale contradiction pour l'enseignant est celle de l'autonomie dont il ne dispose pas comme il le devrait, étant donné qu'il est soumis à divers contrôles internes et externes du système méritocratique dont les exigences vont au-delà de ses capacités physiques et psychiques pour qu'il puisse y répondre de manière adéquate. Cependant la compréhension de ce processus d'aliénation constitue la base de la transformation et de l'émancipation de ceux qui jouent un rôle fondamental dans le développement des capacités de l'autre.

Mots-CLÉs: aliénation, précarisation, travail de l'enseignant, université, enseignement supérieur.

Denise Lemos - Doutora em Ciências Sociais pela Universidade Federal da Bahia. Professora Adjunto do Instituto de Humanidades, Artes e Ciências Prof. Milton Santos da Universidade Federal da Bahia - IHAC/ UFBA. Pesquisadora do Centro de Recursos Humanos - CRH/FFCH/UFBA e consultora do Núcleo de Psicologia Social da Bahia. Atua nas áreas de Psicologia Social, Sociologia do Trabalho, Processos de Comunicação e Relacionamento Interpessoal, Processos grupais, Processos de Aprendizagem, Mudança e Subjetividade. Ênfase em Teorias e Técnicas Grupais e Organização do trabalho. É autora do livro Revolução no trabalho? Núcleo de Psicologia da Bahia, 2002 e de artigos publicados pelo Caderno CRH; Universidade e Sociedade (Brasília). 